\title{
Maxillary pain is the first indication of the presence of multiple myeloma: A case report
}

\author{
XIAO JIAO ZHAO ${ }^{1 *}$, JIAN SUN $^{2 *}$, YING DENG WANG $^{1}$ and LI WANG ${ }^{1}$ \\ Divisions of ${ }^{1}$ Nephrology and ${ }^{2}$ Oral and Maxillofacial Surgery, \\ Shanghai Ninth Peoples' Hospital Affiliated to Shanghai Jiaotong University School of Medicine, Shanghai 200011, P.R. China
}

Received June 7, 2013; Accepted September 11, 2013

DOI: $10.3892 /$ mco.2013.200

\begin{abstract}
Multiple myeloma is a primary malignancy of bone marrow characterized by the clonal proliferation of plasma cells and production of monoclonal immunoglobulin. The disease occurs more frequently in males, with the average age at diagnosis being $\sim 60$ years. The first manifestation of multiple myeloma is varied and depends on the sites and extent of involvement. The predominant clinical symptoms of multiple myeloma are associated with bone pain and renal dysfunction. Neoplastic cells usually produce large amounts of monoclonal immunoglobulin light or heavy chains that can be detected in serum or urine, while plasmacytoma may be identified on marrow biopsy. The present study reported on the case of a 69-year-old male patient presenting with a complaint of a painful lesion in the left maxilla. Physical examination, imaging, laboratory investigations and biopsy were conducted, confirming the diagnosis of multiple myeloma. The results obtained suggest that the dentist should address oral manifestations as first indications of multiple myeloma.
\end{abstract}

\section{Introduction}

Multiple myeloma involves the clonal proliferation of plasma cells based in the bone marrow, with various degrees of differentiation (1). Neoplastic cells usually produce large amounts of monoclonal immunoglobulin light or heavy chains that can be detected in serum or urine (2). Although multiple myeloma is the most common primary bone cancer in adults, in $\sim 95 \%$ of cases, it involves several bones (3).

The etiology of this disease remains to be determined. However, some occupations, exposure to certain chemicals,

Correspondence to: $\mathrm{Dr} \mathrm{Li}$ Wang, Division of Nephrology, Shanghai Ninth Peoples' Hospital Affiliated to Shanghai Jiaotong University School of Medicine, 639 Zhi Zao Ju Road, Shanghai 200011, P.R. China

E-mail: wlyjy73122@126.com

*Contributed equally

Key words: multiple myeloma, maxillary pain overdose irradiation, viruses and genetic factors are considered to be etiologic factors (4).

Myeloma is slightly more prevalent in males and individuals of African-American descent (5). In western countries, the disease is more prevalent in males, with a median and average age at diagnosis of 66 and $~ 60$ years, respectively (6). By contrast, the median and average age at diagnosis is 57 and 55-65 years, respectively (7). The first manifestations that usually present at diagnosis include bone pain (58\%), fatigue (32\%) and weight loss (24\%) (6). The diagnosis of myeloma is usually confirmed by the demonstration of a monoclonal protein (M-protein) in the serum or urine and/or lytic lesions on X-ray together with histological confirmation of a malignant proliferation of plasma cells (8). Treatment involves mainly irradiation, chemotherapy, autologous stem cell transplantation. Prognosis is determined via risk classification by the International Staging System (ISS) (9).

The present study reports a case of painful ulcer-like maxillary mass with multiple myeloma, which was diagnosed based on biopsy of the oral lesion.

\section{Case report}

A 69-year-old male patient presented with a chief complaint of a painful ulcerated lesion in left maxilla, for $\sim 1$ month. Although the patient was treated with antibiotics and cortisol, the lesion was non-healing and became enlarged and painful, resulting in restriction of mouth opening and a weight loss of $4 \mathrm{~kg}$ during the month he was observed. Subsquently, the patient presented to the Shanghai Ninth Peoples' Hospital Affiliated to Shanghai Jiaotong University School of Medicine (Shanghai, China) for further oral and maxillofacial surgery. His previous medical history revealed an episode of lumbar intervertebral disc prolapsed over a period of five years. The pain was exacerbated subsequent to heavy lifting, but had not progressed. The patient had no family history of cancer. Ethics approval for this study was granted by the ethics committee of Shanghai Ninth People's Hospital affiliated to Shanghai Jiaotong University, School of Medicine (Shanghai, China). The patient provided written informed consent.

Peripheral lymphadenopathy was not observed, while the liver and spleen were unpalpable. Intraoral examination revealed an ulcerated and hemorrhagic mass in the left posterior palate near the maxilla body. The lesion extended from 


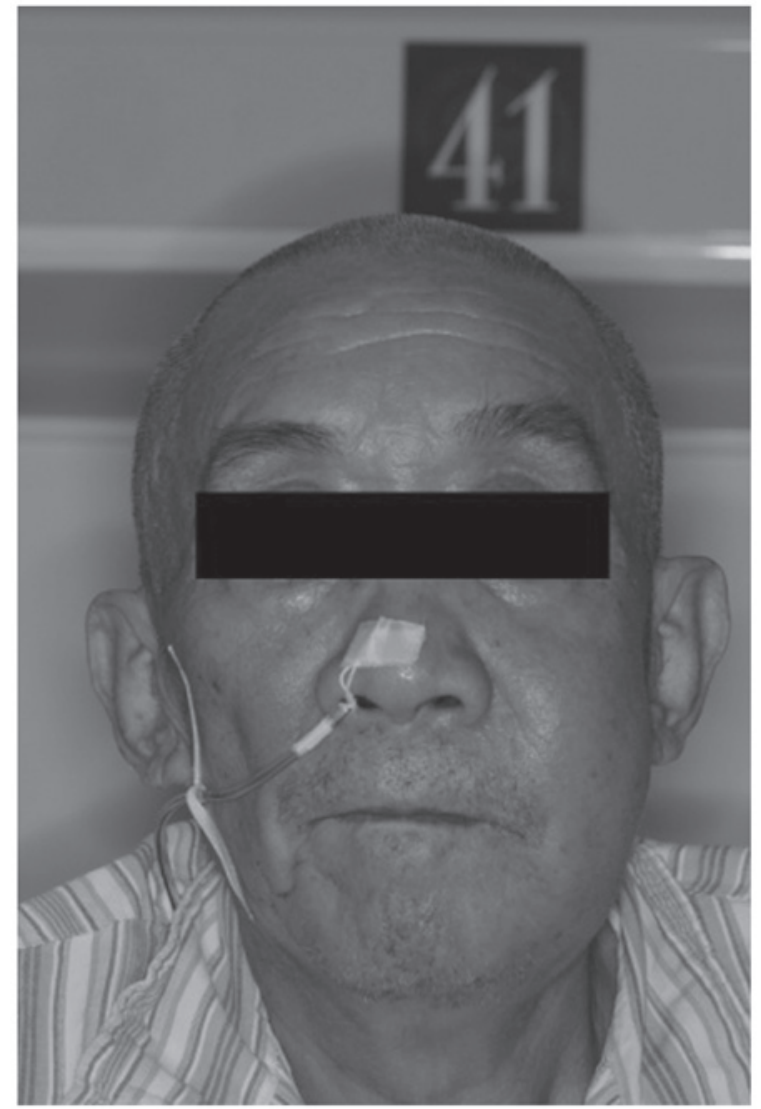

Figure 1. The patient presents left buccal swelling. Since the mouth opening of the patient was restricted, he was administered with nasal feeding.

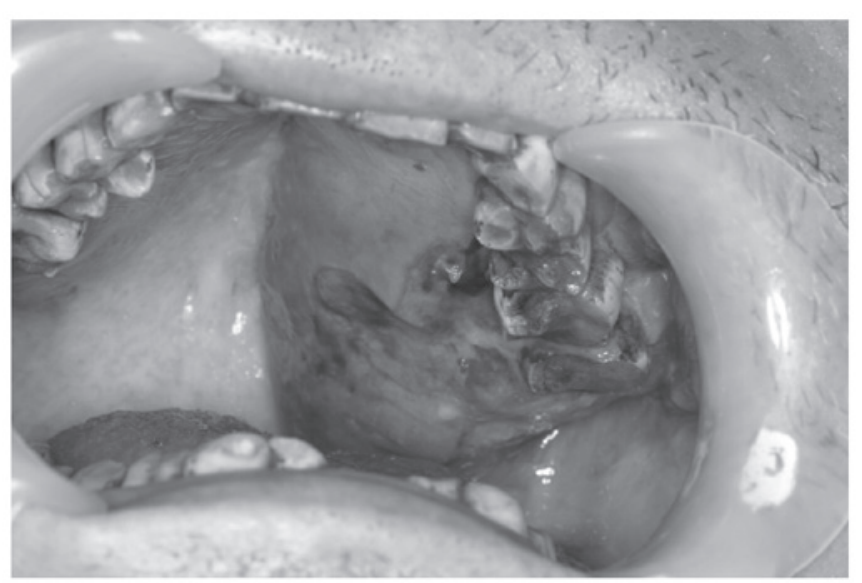

Figure 2. Lesion with a bleeding surface, measuring $\sim 5 \mathrm{~cm}$ diameter.

maxillary left third molar to maxillary left seventh molar. It had an uneven bleeding surface and measured $\sim 5 \mathrm{~cm}$ in its maximum diameter impairing the upper left buccal and palatine gingiva (Figs. 1 and 2).

Contrasted oral and maxillary computed tomography (CT) and magnetic resonance imaging (MRI) showed irregular soft tissue with destruction of the left upper-alveolar bone, periodontium and the maxillary sinus, suggesting a malignant mass (Figs. 3 and 4).

Elevated serum creatinine levels were indicative of multiple organ infiltrations. Consequently, the patient was referred for consultation to the Department of Nephrology and underwent additional examinations.

The lumbar spine MRI revealed multiple vertebral destruction (Fig. 5).

A high serum level of $\beta 2$-microglobulin, hypercalcemia and lactate dehydrogenase were observed, whereas urinary Bence-Jones protein was not identified.

An incisional biopsy was performed under local anesthesia. The histological features indicated sheets of atypical plasma cells (Fig. 6). The immunohistochemical results were positive for CD138, Vs38c, EMA and immunoglobulin G (IgG) (Fig. 7), negative for L26, CD79a and CD3, and $\sim 60-70 \%$ positive for Ki-67 (Fig. 8). Monoclonal staining for $\lambda$ was positive, whereas $\kappa$ was negative. A bone marrow aspiration demonstrated $44 \%$ plasmacytosis.

Serum electrophoresis revealed myeloma protein (M-protein) secreting $\operatorname{IgG}(72.4 \mathrm{~g} / \mathrm{l})$ as well as $\lambda$ light chains. According to these results the diagnosis of multiple myeloma was established as stage IIIB (Durie/Salmon staging system) and symptomatic myeloma presenting as myeloma-related organ and tissue impairment (ROTI, adapted from the International Myeloma Working Group, 2003) (Table I) (10).

The patient was referred for consultation to the Deparments of Hematology and Nephrology. Chemotherapy comprising thalidomide combined with bortezomib-mitoxantronedexamethasone (PMD) was administered. The patient subsequently received autologous stem cell transplantation and remained in remission at the date of the writing of this manuscript.

\section{Discussion}

Multiple myeloma accounts for $\sim 1 \%$ of all types of malignancy and slightly $>10 \%$ of hematologic malignancies (11). Bone marrow examination reveals a large amount of these abnormal plasma cells. Myeloma cells produce abnormal immunoglobulin (M-protein), light chain proteins ( $\kappa$ and $\lambda$ ) and other factors, such as cytokines. Excessive M-protein causes hyperviscosity of the blood. The excessive production of a monoclonal protein (M-protein) may lead to renal dysfunction. Lesions of bone are largely caused by the release of cytokines that promote bone resorption through the upregulation of osteoclast activity, differentiation and maturation $(12,13)$.

Initial findings of the examinations conducted were: anemia in $73 \%$ of patients, bone pain in $58 \%$, renal insufficiency in $48 \%$, hypercalcemia in $28 \%$, palpable liver in $4 \%$ and palpable spleen in $1 \%$ of patients. Lymphadenopathy was observed in $1 \%$ of patients (6). Maxillofacial presentations in patients with multiple myeloma are not uncommon, however, multiple myeloma is often overlooked. Epstein et al (14) examined 783 patients in the literature and indicated that $\sim 14 \%$ of patients had oral manifestations. Oral lesions rarely occured as the first indication of the disease (15-17), whereas jaw lesions are the more common manifestation of multiple myeloma with an incidence varying from $8-15 \%$ (18). As the symptoms vary, multiple myeloma may be misdiagnosed or overlooked in the oral and maxillofacial region.

In the present case the impaired renal function was addressed by physicians. Subsequently, the patient underwent 
A

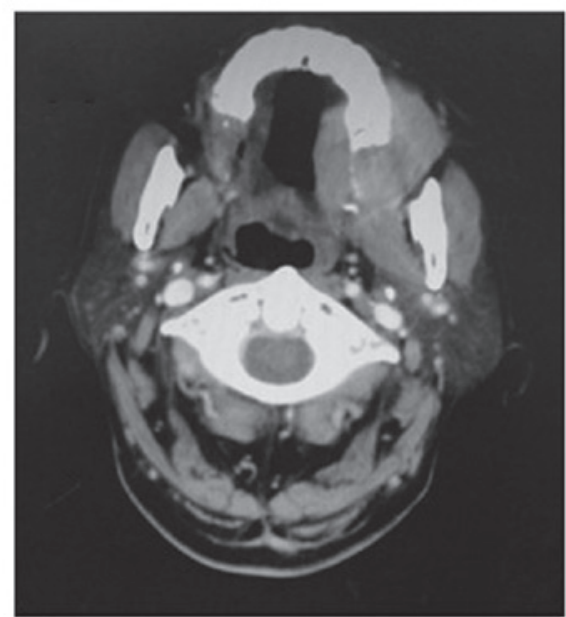

B

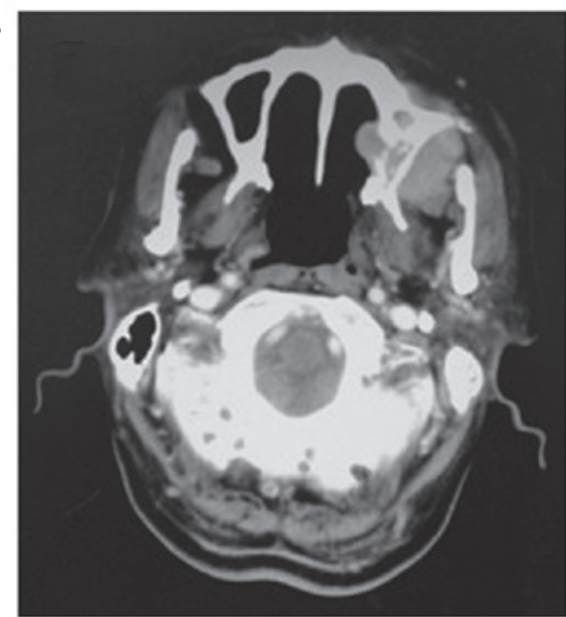

Figure 3. Axial computed tomography scan showing a soft tissue mass with expansion and cortical destruction of the (A) left upper-alveolar bone and (B) maxillary sinus.
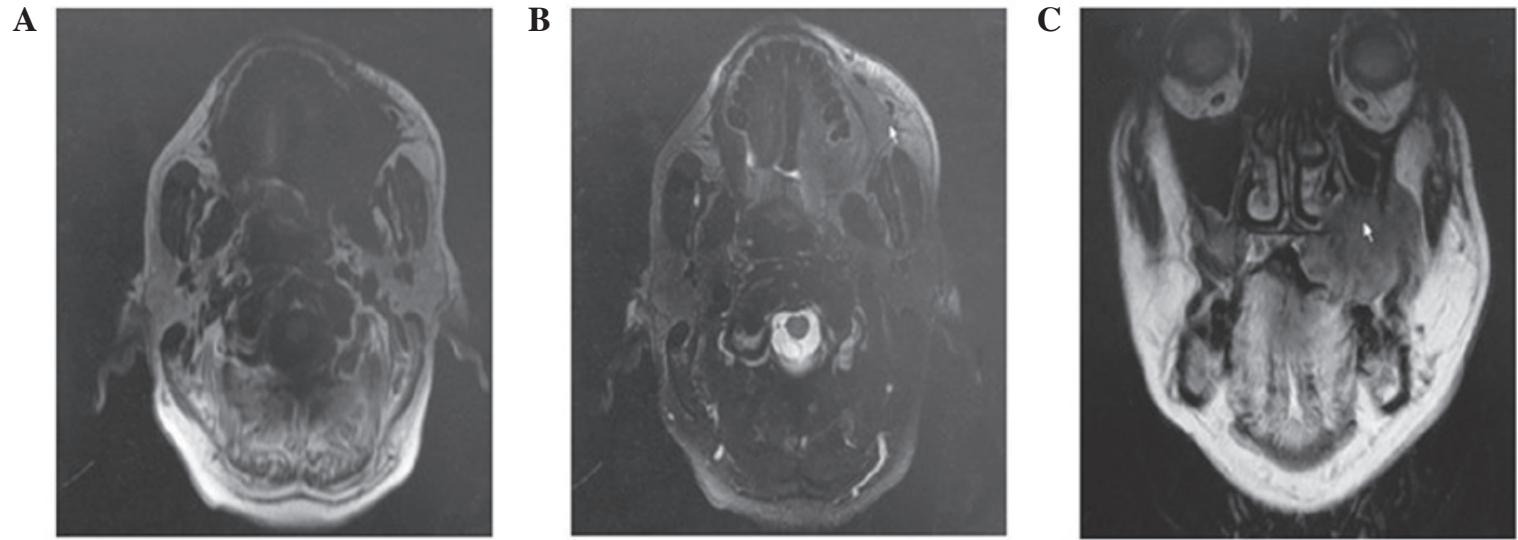

Figure 4. Magnetic resonance imaging showing a mass with (A) low T1- and (B) high T2-weighted signal intensity, and (C) with enhancement following the administration of intravenous contrast.

A

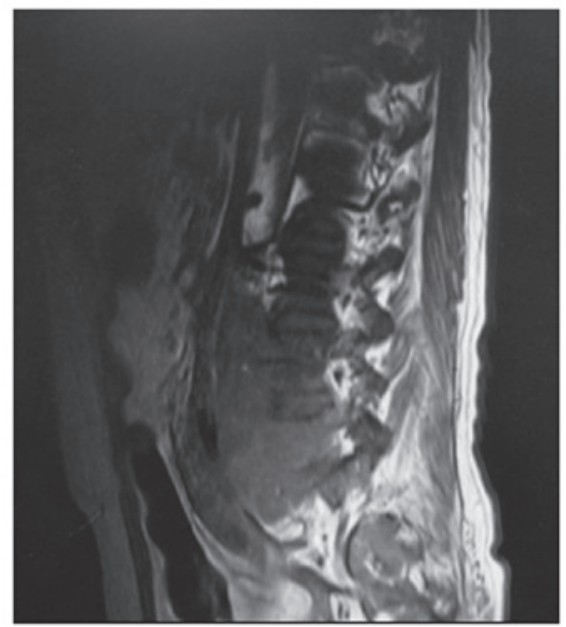

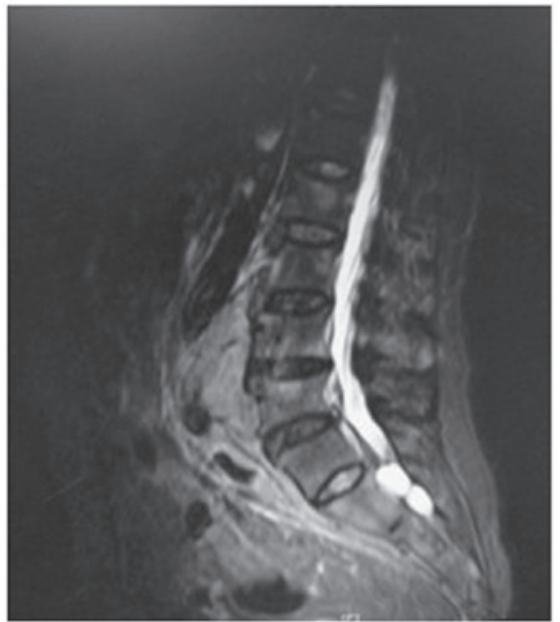

Figure 5. Coronal magnetic resonance image shows multiple destruction on (A) T1- and (B) T2-weighted signal intensity.

chemotherapy instead of surgery due to symptoms including swelling, mass formation, non-healing ulcer, pain, bleeding and fracture of the jawbone, tooth mobility and migration, macroglossia and radiolucent lesions. Osteolytic lesions are reported more frequently in the mandible as compared to the maxilla, particularly in the posterior teeth region, ramus and 
Table I. Values of complete blood count, chemistry measurements and serum protein electrophoresis.

\begin{tabular}{lcc}
\hline Item & Results & Normal range \\
\hline Hemoglobin & $123 \mathrm{~g} / 1$ & $103-151 \mathrm{~g} / 1$ \\
Platelets & $171 \times 10^{9} / 1$ & $101-320 \times 10^{9} / 1$ \\
Serum creatinine & $180 \mu \mathrm{mol} / 1$ & $44-97 \mu \mathrm{mol} / 1$ \\
Calcium & $2.82 \mu \mathrm{mol} / 1$ & $2.08-2.65 \mu \mathrm{mol} / 1$ \\
Lactate dehydrogenase & $220 \mathrm{U} / 1$ & $100-190 \mathrm{U} / 1$ \\
Serum globulins & $25 \mathrm{~g} / 1$ & $32-48 \mathrm{~g} / 1$ \\
$\beta-2$ microglobulin & $16 \mathrm{mg} / 1$ & $0.7-1.8 \mathrm{mg} / 1$ \\
$\gamma$ globulins & $60.1 \mathrm{~g} / 1$ & $6-25 \mathrm{~g} / 1$ \\
Globulin peak in the urine & $2.75 \mathrm{~g} / 24 \mathrm{~h}$ & $0-0.15 \mathrm{~g} / 24 \mathrm{~h}$ \\
\hline
\end{tabular}

Table II. The International Staging System (ISS) for multiple myeloma. ${ }^{a}$

\begin{tabular}{llc}
\hline Stage & \multicolumn{1}{c}{ Criteria } & $\begin{array}{c}\text { Median survival } \\
\text { (months) }\end{array}$ \\
\hline I & $\begin{array}{l}\text { Serum } \beta 2 \text { microglobulin }<3.5 \mathrm{mg} / \mathrm{l} \\
(296 \mathrm{nmol} / \mathrm{l}) \text { and serum albumin }\end{array}$ \\
& $\begin{array}{l}\geq 3.5 / \mathrm{dl}(35 \mathrm{~g} / \mathrm{l} \text { or } 532 \mu \mathrm{mol} / \mathrm{l}) \\
\text { II }\end{array}$ & 62 \\
III & $\begin{array}{l}\text { Neither I or III } \\
\text { Serum } \beta 2 \mathrm{microglobulin} \geq 5.5 \mathrm{mg} / 1\end{array}$ & 45 \\
& $(465 \mathrm{nmol} / 1)$ & 29 \\
\hline
\end{tabular}

${ }^{\mathrm{a}}$ Adapted from Greipp et al (10). ${ }^{\mathrm{b}}$ There are two sub-categories: serum $\beta 2$ microglobulin $<3.5 \mathrm{mg} / \mathrm{l}$, but serum albumin $<3.5 \mathrm{~g} / \mathrm{l}$ or serum $\beta 2$ microglobulin $3.5-5.5 \mathrm{mg}$ irrespective of the serum albumin level.

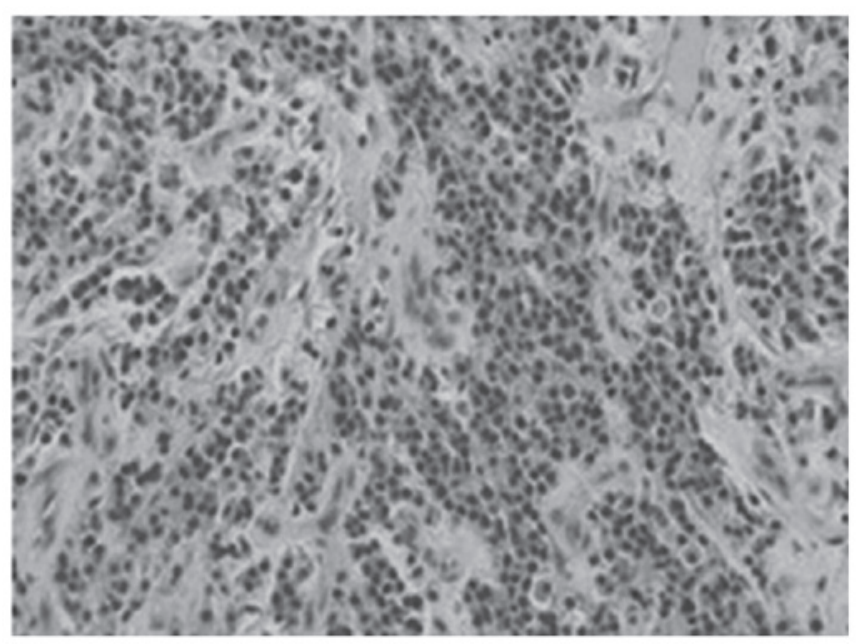

Figure 6. Photomicrograph showing sheets of atypical plasma cells (H\&E staining). Original magnification, $\mathrm{x} 40$.

condylar process, presumably due to greater hematopoietic activity in these areas $(13,18)$. As for the image findings, results of the CT provided detailed information regarding the extent of cortical involvement of the tumor, whereas MRI revealed marrow infiltration as well as diffuse patterns of infiltration that may not be adequately visualized using radiographic imaging alone (2).

An ulcerated, haemorhagic tissue mass of $3 \times 5 \mathrm{~cm}$, arising from the maxillary left third molar to the maxillary left seventh molar, was observed in the present case. Panoramic radiography and MRI/CT revealed an osteolytic lesion in the left posterior maxilla body, haziness of maxillary sinus and multiple destruction and infiltration of the lumber spine. The patient had a previous medical history of lumbar intervertebral disc prolapsed over a period of five years, although the pain associated with the prolapsed disc was not aggravated. The patient's chief complaint was the oral lesion that had shown rapid progression. Therefore, a differential diagnosis between multiple myeloma and multiple metastatic disease should be conducted, particularly in elderly individuals. The differential diagnosis depends on the identification of abnormal monoclonal plasma cells in the full blood count, bone marrow and biopsy, M-protein in the serum or urine and a clinical image consistent with multiple myeloma.

Serum eletrophoresis identifies myeloma protein (M-protein) in $\sim 93 \%$ of the patients. Additionally, $70 \%$ of myelomas secrete $\mathrm{IgG}$, with $\kappa$ light chains being more common (63\%) (6). In the present case, serum protein electrophoresis showed an IgG monoclonal spike of $\sim 72.4 \mathrm{~g} / 1$ with the $\lambda$ light chain. Urine electrophoresis may identify M-protein in $\sim 60 \%$ of patients. Nevertheless, no myeloma protein was detected in the urine of the patient of this study.

Immunohistochemical staining should be performed to confirm plasmacytoma. Up to $85 \%$ of plasma cell neoplasms are positive for EMA, an antibody against epithelial membrane antigen that recognizes the breast epithelial mucin complex (2). CD138 immunostaining of trephine sections is useful in determining the extent of infiltration in selected cases. L26 antibody staining of CD20 molecule, which is usually expressed on mature B cells and a subset of immature B cells, adheres to the expression patterns in normal B-cell development. As a result, plasmacytomas are usually negative for this antibody. Light chain restriction for $\kappa$ or $\lambda$ is usually observed and almost $70 \%$ of plasma cell neoplasms are $\kappa$-positive $(20,21)$.

In this case, the histological and immunohistochemical results led to the diagnosis of malignant plasma-cell lesion. The MRI/CT revealed the presence of multiple oesteolytic lesions. The diagnosis of multiple myeloma was subsequently confirmed by full blood count, incisional biopsy, bone marrow biopsy and laboratory examinations.

The natural history of myeloma is heterogeneous with survival times ranging from a few weeks to $>20$ years. Analysis of prognostic factors is essential to compare outcomes within and between clinical trials. The Durie/Salmon staging system was published in 1975 (22) but has been superseded by the ISS reproduced in Table II (9). The ISS defines three risk categories determined by the serum concentration of $\beta 2$-microglobulin and albumin. The use of staging systems to determine choice of therapy for individual patients remains unproven. As for the patient in this study, the diagnosis was symptomatic myeloma with ROTI staging III (Table II).

Chemotherapy is only suggested for patients with symptomatic myeloma based on the presence of ROTI (10). In 
A

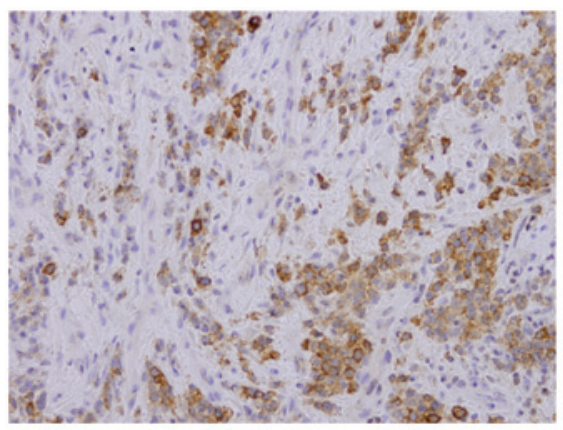

C

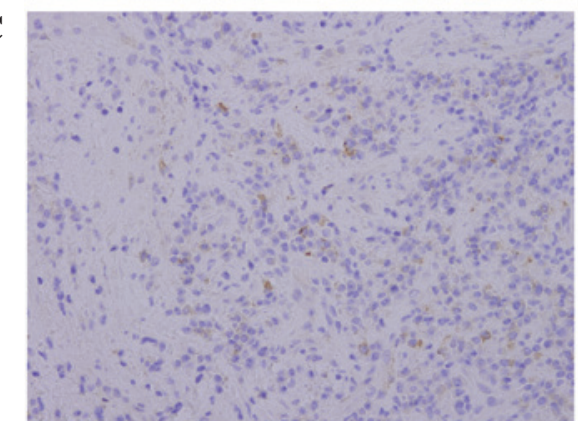

E

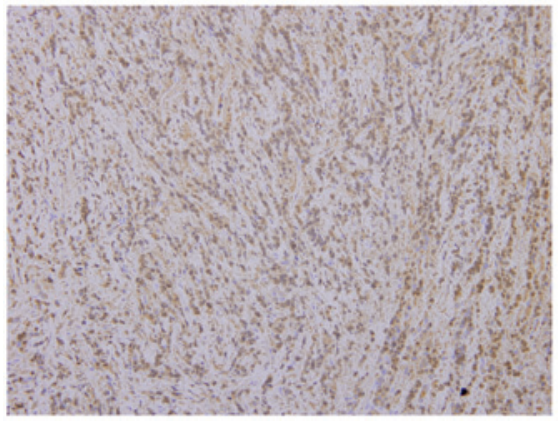

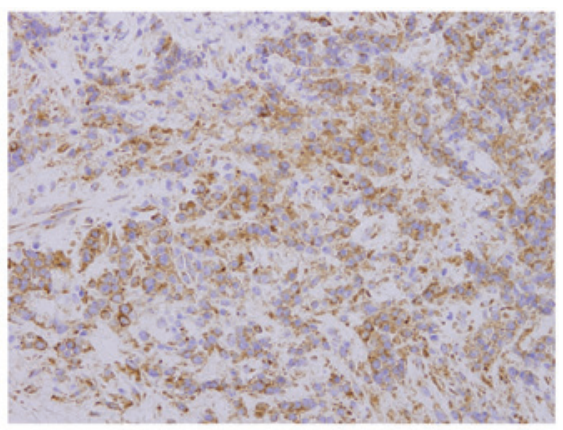

D

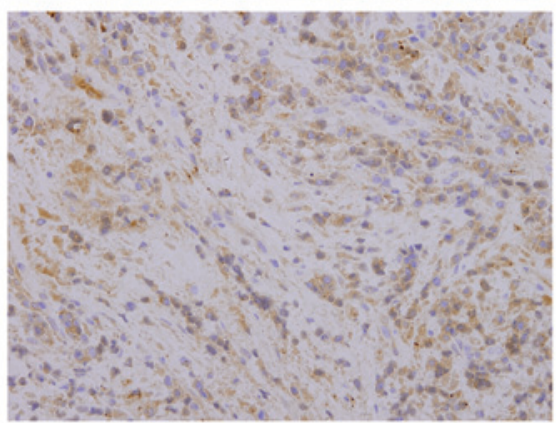

F

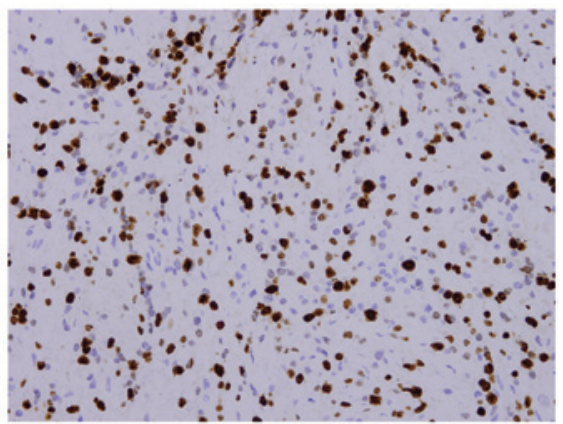

Figure 7. Immunohistochemical results were positive for (A) CD138 (original magnification $\mathrm{x} 40$ ), (B) Vs38c (original magnification $\mathrm{x} 40$ ), (C) EMA (original magnification $\mathrm{x} 40$ ), (D) $\lambda$ (original magnification $\mathrm{x} 40$ ), (E) IgG (original magnification $\mathrm{x} 40$ ) and (F) Ki-67 (original magnification $\mathrm{x} 40$ ).

A

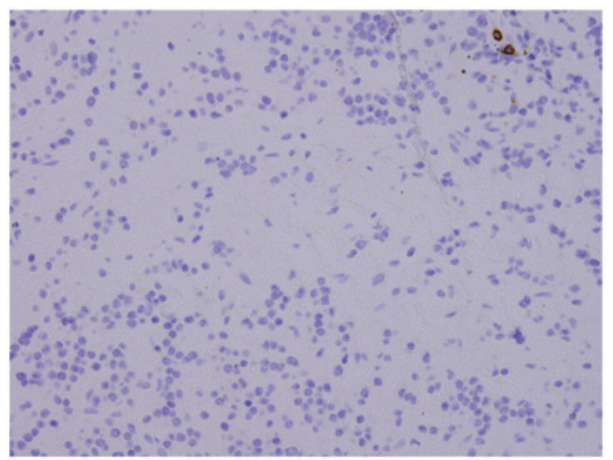

C

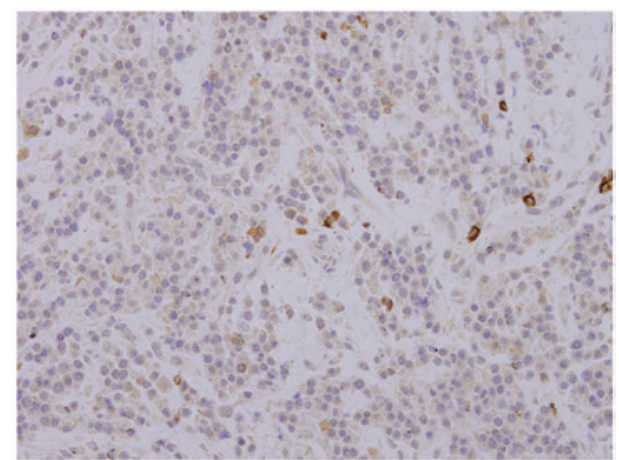

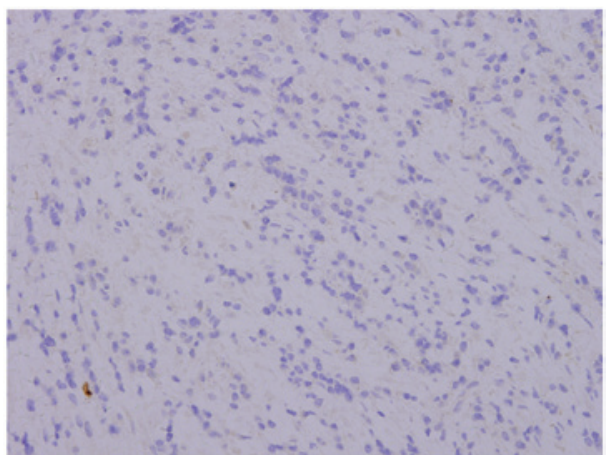

D

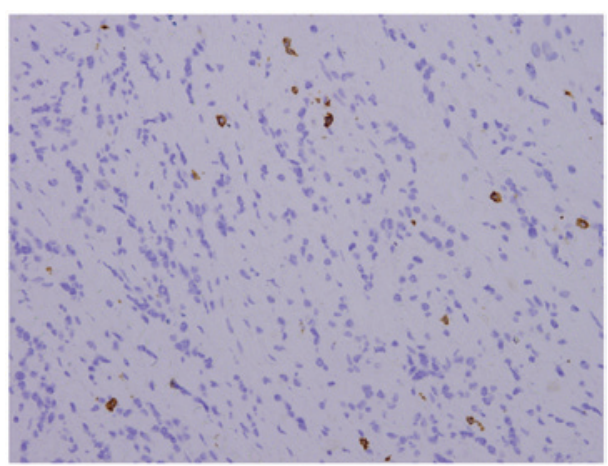

Figure 8. Immunohistochemical results were negative for (A) L26 (original magnification $\mathrm{x} 40$ ), (B) $\kappa$ (original magnification $\mathrm{x} 40$ ), (C) CD79a (original magnification $\mathrm{x} 40$ ) and (D) CD3 (original magnification $\mathrm{x} 40$ ). 
this case, we used PMD combined with thalidomide as an induction therapy prior to autologous stem-cell transplantation. Therefore, the prognosis of this patient is to continue be followed up.

In conclusion, although maxillofacial manifestation in patients with multiple myeloma is not uncommon, multiple myeloma is often overlooked and misdiagnosed. Therefore, findings of this case report suggest that multiple myeloma should be considered as a differential diagnosis and related laboratory/radiographic evaluations should be administered when considering a patient whose chief complaint is unusual maxillary pain.

\section{References}

1. Seoane J, Aguirre-Urizar JM, Esparza-Gomez G, Suarez-Cunqueiro M, Campos-Trapero J and Pomareda M: The spectrum of plasma cell neoplasia in oral pathology. Med Oral 8: 269-280, 2003 (In English).

2. Dinter DJ, Neff WK, Klaus J, Bohm C, Hastka J, Weiss C, Schoenburg SO and Metzgeroth G: Comparison of whole-body MR imaging and conventional X-ray examination in patients with multiple myeloma and implications for therapy. Ann Hematol 88 : 457-464, 2009.

3. Mulligan ME and Badros AZ: PET/CT and MR imaging in myeloma. Skeletal Radiol 36: 5-16, 2007.

4. Beers MH, Porter RS, Jones TV, Kaplan JL and Berkwits M (eds): The Merck Manual of Diagnosis and Therapy. 18th edition. Merck Research Laboratories, Whitehouse Station, NJ, pp1129-1131, 2006.

5. Dores GM, Landgren O, McGlynn KA, Curtis RE, Linet MS and Devesa SS: Plasmacytoma of bone, extramedullary plasmacytoma, and multiple myeloma: incidence and survival in the United States, 1992-2004. Br J Hematol 144: 86-94, 2009.

6. Kyle RA, Gertz MA, Witzig TE, Lust JA, Lacy MQ, Dispenzieri A, Fonseca R, Rajkumar V, Offord JR, Larson DR, et al: Review of 1027 patients with newly diagnosed multiple myeloma. Mayo Clin Proc 78: 21-33, 2003.

7. Mai Y, Qiu L and Li R: The clinical and laboratory features of 432 patients with multiple myeloma. J Leuk Lymphoma 13: 198-201, 2004.

8. Durie BG, Kyle RA, Belch A, Bensinger W, Blade J, et al: Myeloma management guidelines: a consensus report from the Scientific Advisors of the International Myeloma Foundation. Hematol J 4: 379-398, 2003.
9. Greipp PR, San Miguel J, Durie BG, et al: International staging system for multiple myeloma. J Clin Oncol 23: 3412-3420, 2005.

10. International Myeloma Working Group: Criteria for the classification of monoclonal gammopathies, multiple myeloma and related disorders: a report of the International Myeloma Working Group. Br J Haematol 121: 749-757, 2003.

11. Bird JM, Owen RG, D'Sa S, Snowden JA, Pratt G, et al: Guidelines for the diagnosis and management of multiple myeloma 2011. Br J Haematol 154: 32-75, 2011.

12. Nau KC and Lewis WD: Multiple myeloma: diagnosis and treatment. Am Fam Physician 78: 853-859, 2008.

13. Ashcroft AJ, Davies FE and Morgan GJ: Aetiology of bone disease and the role of bisphosphonates in multiple myeloma. Lancet Oncol 4: 284-292, 2003.

14. Epstein JB, Emerton S, Guglietta A and Le N: Assessment of epidermal growth factor in oral secretions of patients receiving radiation therapy for cancer. Oral Oncol 33: 359-363, 1997.

15. Mozaffari E, Mupparapu M and Otis L: Undiagnosed multiple myeloma causing extensive dental bleeding: report of a case and review. Oral Surg Oral Med Oral Pathol Oral Radiol Endod 94: 448-453, 2002.

16. Pinto LS, Campagnoli EB, Leon JE, et al: Maxillary lesion presenting as a first sign of multiple myeloma: case report. Med Oral Patol Oral Cir Bucal 12: E344-E347, 2007.

17. Shah A, Ali A, Latoo S and Ahmad I: Multiple Myeloma presenting as Gingival mass. J Maxillofac Oral Surg 9: 209-212, 2010.

18. Zachriades N, Papanicolaou S, Papavassiliou D, Vairaktaris E, Triantafyllou D and Mezitis M: Plasma cell myeloma of the jaws. Int J Oral Maxillofac Surg 16: 510-515, 1987.

19. Pisano JJ, Coupland R, Chen SY and Miller AS: Plasmacytoma of the oral cavity and jaws: a clinicopathologic study of 13 cases. Oral Surg Oral Med Oral Pathol Oral Radiol Endod 83: 265-271, 1997.

20. Hsi ED and Yegappan S: Lymphoma immunophenotyping: a new era in paraffin-section immunohistochemistry. Adv Anat Pathol 8: 218-239, 2001

21. Bayer-Garner IB, Prieto VG and Smoller BR: Detection of clonality with $\kappa$ and $\lambda$ immunohistochemical analysis in cutaneous plasmacytomas. Arch Pathol Lab Med 128: 645-648, 2004.

22. Durie BG and Salmon SE: A clinical staging system for multiple myeloma. Correlation of measured myeloma cell mass with presenting clinical features, response to treatment, and survival. Cancer 36: 842-854, 1975. 